\title{
Comparison of Aerobic Training Methods on V02 Max, Body Composition and Anaerobic Power
}

Amanda M. Crawford, Cliffa Foster, Chris Poole, Brandon Bushey, Colin Wilborn

University of Mary Hardin - Baylor

Int J Exerc Sci 2(1): S16, 2009. Recent research has utilized intensity as a primary means to define training methods for improving aerobic capacity (VO2 max). Alternative ways of classifying training techniques must be examined to elucidate optimal practices for aerobic capacity enhancement. PURPOSE: To investigate the potential impact of various aerobic training methods on V02, body composition and anaerobic power. METHODS: Thirtyfour healthy male \& female subjects (18-30yrs) participated in an equated volume supervised running workout for six weeks utilizing two alternate training methods. Group one $(\mathrm{N}=17,21 \pm 3 \mathrm{yr})$ participated in Interval Training Distance (ITD) and group two ( $=17,21 \pm 3 \mathrm{yr}$ ) participated in Long Slow Distance (LSD). All subjects participated in a familiarity session (FAM), a Pre-Test (T1) and a Post-Test (T2) . Each testing session consisted of a V02 Max, a 30 second Wingate and body composition assessment. Data were analyzed by a two-way ANOVA with repeated measures. Significance was set at $p<0.05$ and adopted throughout. RESULTS: The ITD and LSD groups experienced significant increases $(\mathrm{p}<0.001)$ in VO2 max, with $9.05 \%(4.19 \pm 4.15 \mathrm{ml} / \mathrm{kg} / \mathrm{min})$ and $3.18 \%(1.39 \pm 3.67 \mathrm{ml} / \mathrm{kg} / \mathrm{min})$ increases respectively. A significant interaction $(\mathrm{p}<0.05)$ in VO2 max occurred between groups, as the ITD group displayed a $302 \%$ greater increase when compared to the LSD group. Body fat percentage significantly decreased $(p<0.01)$ in the ITD $(1.08 \pm 1.90 \%)$ and LSD $(1.55 \pm 3.21 \%)$ groups, while a significant reduction $(p<0.05)$ in total body weight was also observed. CONCLUSION: The findings of this study suggest that the ITD training method has a greater impact on aerobic capacity than LSD training method. However, both ITD and LSD training methods had a significant impact on aerobic capacity, body weight, and body composition.

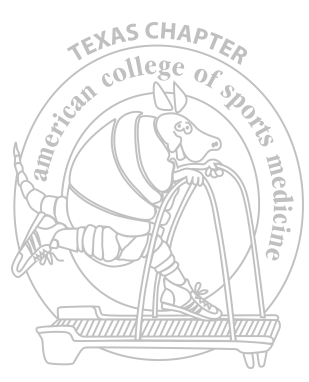

S16 